\title{
High Performance Pseudocapacitor Electrode Material Fabricated by Pulse Electro-Synthesized Cobalt Oxide Nanostructures
}

\author{
Mustafa Aghazadeh ${ }^{1}$, Amir Rashidi ${ }^{l}$, Parviz Norouzi ${ }^{2,3, *}$ and Mohammad Ghannadi Maragheh ${ }^{1}$ \\ ${ }^{1}$ NFCRS, Nuclear Science and Technology Research Institute (NSTRI), P.O. Box 14395-834, Tehran, \\ Iran \\ ${ }^{2}$ Center of Excellence in Electrochemistry, University of Tehran, Tehran, Iran \\ ${ }^{3}$ Biosensor Research Center, Endocrinology and Metabolism Molecular-Cellular Sciences Institute, \\ Tehran University of Medical Sciences, Tehran, Iran. \\ *E-mail: norouzi@khayam.ut.ac.ir
}

doi: $10.20964 / 2016.12 .116$

Received: 29 August 2016/ Accepted: 23 October 2016 / Published: 10 November 2016

High surface $\mathrm{Co}_{3} \mathrm{O}_{4}$ nanosheets were prepared were synthesized by a facile two-step approach, including a pulsed cathodic deposition without any surfactant and followed calcination of precursor. The as-deposited material was composed of pure $\beta$-cobalt hydroxide with sheet-like morphology. The calcined product was cubic spinel $\mathrm{Co}_{3} \mathrm{O}_{4}$ phase with sheet texture according to X-ray diffraction and scanning electron microscopy. The oxide formation on heating was discussed based on the thermogravimetric data. Brunauer-Emmett-Teller (BET) measurement showed the high surface area of about $164 \mathrm{~m}^{2} \mathrm{~g}^{-1}$ for the prepared cobalt oxide nanosheets. The pseudocapacitor capacitance of the prepared electrode was as high as $501.6 \mathrm{~F} \mathrm{~g}^{-1}$ at a current density of $2 \mathrm{~A} \mathrm{~g} \mathrm{~g}^{-1}$, and the cycling stability remained about $89.9 \%$ after 2000 cycles. The fabricated electrode delivered energy and power densities of $29.43 \mathrm{Wh} / \mathrm{Kg}$ and $0.33 \mathrm{~W} / \mathrm{g}$, respectively. These results confirmed the high pseudocapacitive performance of the prepared active nanomaterials.

Keywords: $\mathrm{Co}_{3} \mathrm{O}_{4}$; Nanoplates; Pulse Electrodeposition; Heat-treatment; Supercapacitive performance

\section{$\underline{\text { FULL TEXT }}$}

(C) 2016 The Authors. Published by ESG (www.electrochemsci.org). This article is an open access article distributed under the terms and conditions of the Creative Commons Attribution license (http://creativecommons.org/licenses/by/4.0/). 